транспортных и хронометрических (кинетических) процессов переноса вещества, энергии и момента импульса [10],a также обязательных незамедлительных реагирований, принятия решений, поскольку их игнорирование может привести к утери большого количества денежных средств и привести к необратимым последствиям.

$$
* * *
$$

1. Сень Л.И., Лысенко Л.В., Минаев А.Н., Пермяков В.В., Ильяшенко Н.Г., Воронов В.И. Основы проектирования парогенераторов, работающих на морской воде. Учебное пособие для специальности 0525 «Судовые энергетические установки» / Ответственный за выпуск Ю.В. Якубовский. Владивосток. 1978.

2. Сень Л.И., Пермяков В.В., Ильяшенко Н.Г., Воронов В.И., Лысенко Л.В., Дарменко А. В. Термическая обработка морских и сточных вод для парогенераторных установок. В сборнике: Теплообмен и гидрогазодинамика при кипении и конденсации. 1979. С. 123-124.

3. Воронов В.И. Исследование рабочего процесса в высокотемпературном пленочном контактном нагревателе морской воды судовой парогенераторной установки. Диссертация на соискание ученой степени кандидата технических наук / Владивосток, 1983.

4. Воронов В.И. Международная логистика (Электронный ресурс). Вестник университета (Государственный университет управления). 2014. с.700.

5. Воронов В.И., Воронов А.В., Ермаков А.А. Внешнеторговая статистика в развитии международного маркетинга и логистики. Маркетинг. 2014. № 1 (134). С. 90-96.

6. Аникин Б.А., Воронов В.И. Развитие и взаимосвязь основных концепций управления предпринимательскими организациями. Транспорт: наука, техника, управление. 2006. № 4, с. 7-14.

7. Воронов В.И. Методологические аспекты экономического обеспечения логистических систем управления. Вестник университета (Государственный университет управления). 2006. № 4. С. 11.

8. Воронов В.И., Кривоносов Н.А. Савостьянок Г.Н., Кожанова В.В Инновационные технологии в логистике. Научно-аналитический журнал: «Инновации и инвестиции» № 4, 2015- стр. 2-4.

9. Воронов В.И., Пичейкина А.С. Основные аспекты логистического консалтинга. Вестник университета (Государственный университет управления). 2007. Т. 1. № 19. С 151-159.

10. Воронов В.И., Лысенко Л.В., Андреев В.В. Теоретические основы логистических, финансовых транспортно-кинетических процессов. Вестник Пермского национального исследовательского политехнического университета. Электротехника, информационные технологии, системы управления. 2007. № 7. C. 139.

11. Рубинштейн А., Музычук В. Культура и рынок. Опекаемые блага. 2014. С. 42

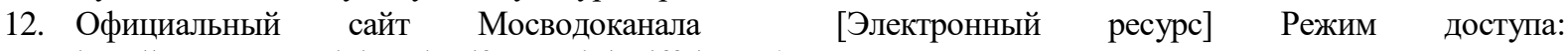
http://www.mosvodokanal.ru/forpeople/tariffs/, свободный.

\title{
Кротенко Т.Ю. \\ Самостоятельная работа студентов в рамках компетентностного подхода к обучению
}

Государственный университет управления (Россия, Москва)

doi: $10.18411 / l j-31-10-2017-31$

idsp: 000001:lj-31-10-2017-31

\section{Аннотация}

Компетенции определяют набор видов деятельности, которые должен осуществлять профессионал в конкретной области на определенном уровне. Модель компетенций в такой профессиональной области, как менеджмент, более точно раскрывает характер деятельности менеджера по сравнению с набором квалификационных характеристик.

Ключевые слова: компетенция, менеджмент, лидерство, эмоциональный интеллект, рефлексивность мышления.

В отличие от традиционного квалификационного подхода компетентностный подход к обучению отражает требования не только к содержанию образования (что должен знать, уметь и какими навыками владеть выпускник вуза в профессиональной 
области), но и к поведенческой составляющей (способностям применять знания, умения и навыки для решения задач профессиональной деятельности).

Модель компетенций в такой профессиональной области, как менеджмент, более точно раскрывает характер деятельности менеджера по сравнению с набором квалификационных характеристик.

Учебная дисциплина «Менеджмент» имеет целью не столько получение знаний, сколько формирование определенного типа профессионального мышления и деятельности, соединение знаний с практикой, формирование устойчивых и фундаментальных представлений о менеджменте.

Самостоятельная работа студентов по дисциплине «Менеджмент» предполагает так же закрепление знаний и умений, полученных на теоретических и практических занятиях.

Какие компетенции нужны для выполнения менеджером определенных рабочих задач? Автор сформулировал ниже компетенции руководителя с описанием поведенческих проявлений человека, обладающего этой компетентностью на уровне опыта.

1. Понимание бизнеса/Лидерство в стратегическом предвидении. Имеет целостное видение бизнеса Компании, разбирается в различных его аспектах. Имеет полное представление о продуктах и услугах, предлагаемых Компанией. Понимает, как корпоративную стратегию можно реализовать в своем подразделении. Ориентируется на стратегию, прежде чем приступать к действиям. Принимая управленческие решения, ориентируется на бизнес-показатели. Знает принципы построения и функционирования розничной и оптовой сетей. Хорошо ориентируется на рынке продукции, выделяет основные тенденции, отслеживает динамику. Знает основных игроков рынка, их конкурентные преимущества и недостатки. Создает видение будущего компании. Формулирует стратегические цели. Разрабатывает пути их достижения. Доводит до всех сотрудников сформулированное видение будущего. Не всегда способен вселить в сотрудников веру в это будущее.

2. Предпринимательская инициатива. Постоянно ищет способы развития бизнеса. Каждый новый факт, новую порцию информацию анализирует, пытаясь нащупать возможности для развития бизнеса. Постоянно задается вопросом: “А что если попробовать?” Формулирует новые идеи, позволяющие расширять бизнес. Прежде чем приступать к внедрению идеи, анализирует ее с точки зрения их реалистичности и коммерческой выгоды.

3. Принятие решений. Быстро анализирует большие объемы информации, тщательно прорабатывая материал. Отделяет важную информацию от второстепенной. Точно понимает, какая информация и в каком объеме нужна для принятия взвешенного решения. Выделяет причины проблемы. Выдвигает несколько вариантов её решения. Относительно каждого варианта просчитывает риски и возможные альтернативы. Берёт на себя ответственность за принятие решений.

4. Планирование/Управление исполнением. Анализирует комплексные процессы. Выделяет влияющие факторы. Видит бизнес целостно, понимая взаимосвязь различных, в том числе далеких друг от друга, явлений. Создает планы, позволяющие повысить эффективность рабочих процессов. Для решения вопроса создает и формулирует больше чем один план. Меняет свои подходы к работе в соответствии с переменами внутри и вне Организации. Умеет адекватно трансформировать общую цель в ряд конкретных задач. Распределяет задания между подчиненными с учетом их возможностей, знаний и навыков. Выделяет ключевые параметры и способы контроля. Обеспечивает понимание подчиненными цели, задач и параметров контроля. Последовательно осуществляет контроль промежуточных и конечных результатов.

5. Мотивирование/Лидерство в команде. Умеет заручиться поддержкой и получить согласие других действовать в нужном направлении. Точно оценивает моральный фактор в работе. Мотивирует других, увязывая воедино организационные и индивидуальные 
цели. Дает конструктивную обратную связь о результатах. Награждает правильное поведение. Берет на себя ответственность за поддержание нужного уровня мотивации у всех членов команды.

6. Межфункциональное взаимодействие. Разделяет и транслирует нормы и правила, принятые в Компании. В любой ситуации расставляет приоритеты, руководствуясь интересами Компании. Имеет ясное представление о вкладе других направлений в деятельность Компании. Координирует свои действия с интересами смежных подразделений. Предвосхищает возникновение конфликтных ситуаций и не допускает их усугубления. Предлагает решения, удовлетворяющие потребности других подразделений. Открыто обсуждает трудности и проблемы в работе Компании с теми членами Управленческой команды, от которых зависит принятие решений. Ориентирован на решение проблемы.

7. Гибкость/Инновативность. Воспринимает перемены как нормальную рабочую ситуацию. Гибко реагирует на изменения. Оперативно перестраивает свою работу и работу своего подразделения с учетом новых обстоятельств. Активно использует новую информацию и новые подходы в своей работе. Является проводником организационных изменений. Успешно справляется с сопротивлением изменениям в коллективе. Создаёт стандарты и процедуры, поддерживающие инициативы подчинённых. Видит свои сильные и слабые стороны. Запрашивает обратную связь от коллег, руководства и подчиненных. Конструктивно воспринимает критику. Корректирует поведение в целях повышения своей менеджерской эффективности.

8. Ориентация на результат и достижения.

Нацелен на конечный результат, а не только на процесс. Упорен. Никогда не останавливается, пока не достигнет цели, сколь бы сложно это не было. Верит в успех. Прикладывает все необходимые усилия для достижения результата. Концентрирует свою волю на преодолении трудностей. Не сдается, столкнувшись с временными неудачами. Ставит перед своей командой амбициозные, хотя и реалистичные цели.

$$
* * *
$$

1. Кротенко Т.Ю. Компетентностный подход в реализации корпоративной социальной ответственности (тезисы доклада). - Управление экономикой в стратегии развития России: Материалы Международного управленческого форума: Вып.1 / ГУУ. - М.: «Издательство ГУУ», 2014.

2. Коротков Э.М., Жернакова М.Б., Кротенко Т.Ю. Управление изменениями: преобразующий менеджмент. - Учебник, 2-е дополненное и доработанное издание. - М.: «Изд-во Юрайт», 2015.

3. Кротенко Т.Ю. Проблемы образования и формирования преобразующего мышления. - Актуальные направления фундаментальных и прикладных исследований. Материалы XIII международной научнопрактической конференции. - М.: Н.-и. ц. «Академический», 2017.

\section{Майданов Д.А. \\ Исследование развития лизинга на рынке инвестиционных товаров}

Государственный университет управления (Россия, Москва)

doi: $10.18411 / l j-31-10-2017-32$

idsp: 000001:lj-31-10-2017-32

\section{Аннотация}

В данной статье рассматриваются и исследуются лизинговые операции в России на рынке инвестиционных товаров. Выявляются достоинства и недостатки развития лизинга в различных сферах общественной деятельности. Обсуждаются наиболее удобные ведения бизнеса с помощью лизинга.

Ключевые слова: Лизинговый механизм, ипотека, кредит, потребительский лизинг, инвестиционные товары, недвижимость, оборудование. 